\title{
Synthetic Copulin Does Not Affect Men's Sexual Behavior
}

\author{
Megan N. Williams ${ }^{1} \cdot$ Coren Apicella $^{1}$
}

Received: 12 September 2017 / Revised: 2 November 2017 / Accepted: 7 November 2017 / Published online: 21 November 2017

C) The Author(s) 2017. This article is an open access publication

\begin{abstract}
Chemical communication plays an important role in the social interactions and mating behavior of diverse animal taxa; yet its role in humans remains equivocal. Using a randomized, placebo-controlled experiment involving 243 male participants, we test whether exposure to synthetic copulin - a mixture of volatile fatty acids secreted vaginally in primates, increases 1) men's sexual motivation using an incentivized behavioral task, 2) self-reported willingness to take sexual risks, 3) preference for short-term mating, 4) perceptions of female attractiveness and 5) self-reported mate value. Because chemical receptors are found throughout the body and human chemosensory pathways have yet to be definitively identified, we also manipulate the location of copulin exposure (i.e. olfactory epithelium versus epidermal keratinocytes in the genital region). Finally, we examine whether prior sexual experience mediate any behavioral effects. Unlike previous reports, we fail to find any effects of copulin exposure on measures of men's sexual behavior.
\end{abstract}

Keywords Chemical communication $\cdot$ Pheromones $\cdot$ Copulins $\cdot$ Mating

\section{Introduction}

Chemical communication is the most ubiquitous form of communication among organisms (Wyatt 2014). It is used to track prey, detect predators, recognize in-group conspecifics and identify mates (Engen 1983; for review, Carlson 2013). Historically, the relevance of chemical communication in primates, including humans, has been criticized due to selection for trichromacy and regression of the olfactory bulb (Barton et al. 1995). Instead, primates have been classified as microsmatic because, compared

Megan N. Williams

meganwil@sas.upenn.edu

1 University of Pennsylvania, 3720 Walnut Street, Philadelphia, PA 19104, USA 
to other mammals like rodents, primates have proportionally smaller olfactory bulbs, less surface area in the nasal cavity dedicated to the olfactory epithelium and more pseudogenized olfactory receptor genes (Smith and Bhatnagar 2004). Recently, however, these views have been challenged. First, there is no correlation between the size of the olfactory cortex, the olfactory epithelium or the number of olfactory receptors and olfactory function (Laska and Freyer 1997; Laska and Teubner 1998, 1999a, b; Laska et al. 2005) - the most important factor in odor discrimination tasks is the species-specific ecological validity of the stimuli tested (Laska et al. 2005). Second, research with Lemuridae, Indridae, Callitrichidae, and Cebidae suggest that chemical signals are involved in diverse behaviors, such as territorial marking, self and kin recognition as well as reproductive behaviors (Kaplan et al. 1977; Rogel 1978; Epple 1986; Epple et al. 1986; Millhollen 1986). Third, humans are capable of recognizing at least one trillion olfactory stimuli (Bushdid et al. 2014) and perform similarly to canines on scent-tracking tasks (Porter et al. 2007). Together, these findings suggest that we may have radically underestimated the role of olfaction in human behavior.

Humans use olfaction to avoid spoiled foods and to detect the presence of harmful environmental pollutants (Engen 1983). Odors also affect mood and memories. Exposure to pleasant odorants can improve mood (for review, Maddocks-Jennings and Wilkinson 2004; Trotier 2011) and odor-elicited memories are often more emotional and sometimes more accurate than other sensory-elicited memories, due to the olfactory bulb's direct projection to the limbic system (Herz et al. 2004). In fact, olfactory loss is an important diagnostic indicator in medicine as it is often the first symptom of neurodegenerative diseases within the brain, including those associated with Alzheimer's and Parkinson's (Rawson et al. 2012). In short, olfaction is important in humans.

\section{Chemical Signals}

While there is little debate as to what constitutes an odor, research on pheromones is more contentious because an agreed upon definition for pheromone is lacking. Traditionally, scientists have defined pheromones in mammals as non-volatile chemicals transduced by the vomeronasal organ (VNO) and transmitted to the accessory olfactory bulb (AOB) (Savic et al. 2001; Witta and Wozniak 2006; Trotier 2011). Since humans lack an $\mathrm{AOB}$ and a functional $\mathrm{VNO}$, it follows that, according to this definition, pheromone signaling cannot exist. Yet this type of communication is unquestioned in many species, like dogs and elephants, which also lack a functional VNO (Grus et al. 2005). Moreover, a number of studies show that the VNO is unnecessary for the detection of chemical signals (Hudson and Distel 1986; Savic et al. 2001; Barton 2006; Witta and Wozniak 2006; Trotier 2011). For instance, sexual behavior in female pigs is influenced by androstenone even after their VNO has been blocked (Dorries et al. 1997). In ewes with a removed VNO, ovulation is still induced upon smelling a ram (Signoret 1991). These, and other findings, suggest that the pathway for mammals to communicate via chemicals is not limited to the VNO. Many researchers now prefer the term chemical signal instead of pheromone due to the confusion and conflict surrounding pheromone's definition. Thus, in this paper, we also employ this terminology and define a chemical signal as any chemical emitted by one individual that 
alters either the behavior or physiology of another organism (Luscher and Karlson 1959; Wyatt 2014).

Recent studies have found that chemoreceptors are not unique to the olfactory and gustatory systems; they exist in tissues throughout the human body. Chemoreceptors have been discovered in spermatogenic cells (Spehr et al. 2003), epidermal keratinocytes (Busse et al. 2014), muscle tissue (Griffin et al. 2009), the kidneys (Pluznick et al. 2009), and pulmonary neuroendocrine cells (Gu et al. 2014). The chemo-attractants for many of these receptors have not been isolated, but in the examples that have, the results are remarkable. For example, synthetic sandalwood binds to chemical receptors in epidermal keratinocytes and causes an increase in rapidity of wound healing (Busse et al. 2014). It is currently unknown whether biological odorants could act as chemo-attractants, binding to chemical receptors in various tissues, including the olfactory epithelium or epidermal keratinocytes in the genital region, and influence sexual arousal, ejaculate volume, or even sexual behaviors. The current study undertakes the first exploration of an alternative pathway for chemical communication. Although a long shot, we test if copulin affects men's behavior through a genital epidermal keratinocyte pathway, in addition, to testing the conventional olfactory pathway.

\section{Odors and Attraction}

The most prolific work examining the role of olfaction in mate selection involves human leukocyte antigen (HLA); more commonly referred to by its rodent counterpart - the major histocompatibility complex (MHC). HLA is an immunologically important group of genes implicated in self versus other recognition. Research demonstrates that humans use HLA-mediated odors to inform mate assessment (for review, Havlicek and Roberts 2009). HLA-disassortative mating may have been selected for in order to increase offspring pathogen resistance by the avoidance of inbreeding (Wedekind et al. 1995; Wedekind and Füri 1997; Jacob et al. 2002; Thornhill et al. 2003; Santos et al. 2005; Roberts et al. 2008).

Similar work focuses on axillary secretion exposure, with most studies reporting behavioral and physiological effects (Brooksbank and Haslewood 1961; Cleveland and Savard 1964; Schleidt and Hold 1982; Cutler et al. 1998; McCoy and Pitino 2002; Grammer et al. 2003; Witta and Wozniak 2006; Saxton et al. 2008; Savic and Berglund 2010). For instance, Black and Biron (1982) demonstrated female participants rated male confederates wearing a $3 \alpha$ androstenol exaltolide (synthetic androstenol) perfume more attractive. Androstenol is a testosterone derivative found in high concentrations in post-pubescent male axillary secretions (Parma et al. 2017).

While much work has examined effects of male axillary secretions, there has been less attention given to female odors. The empirical work that exists concentrates on shifts in women's odor corresponding with shifts in their menstrual cycle (for review, Haselton and Gildersleeve 2011). These studies find that 1) men prefer the body odor of ovulating women (Doty et al. 1975; Singh and Bronstad 2001) and 2) odor samples taken from women at high conception risk increase men's testosterone (Jütte and Grammer 1997; Miller and Maner 2010, 2011), sexual arousal (Miller and Maner 2010, 2011) and risk-taking (Miller and Maner 2011; also see Cerda-Molina et al. 2013). 


\section{Copulin}

In this paper, we assess the effects of copulin - a mixture of 5 aliphatic-acids reported to fluctuate with the menstrual cycle - on men's behavior (Michael et al. 1975; Preti and Huggins 1975. The behavioral and psychological effects of copulin have been documented in studies with non-human primates (Michael and Keverne 1968; Michael et al. 1971; Michael and Zumpe 1982; Cerda-Molina et al. 2006; Matsumoto-Oda et al. 2003; but see Goldfoot et al. 1976). Yet, only a few human copulin behavioral studies have been published and their results are conflicting.

Michael et al. (1975), as well as Preti and Huggins (1975), used gas chromatography to analyze the chemical content of human vaginal secretions. They found women produce copulin at greater concentrations during the follicular phase and these concentrations drop after ovulation (Michael et al. 1975). The authors also report that hormonal contraceptives reduced the overall content of copulin in vaginal secretions and eliminated the fluctuations in amount across the cycle. All women sampled $(N=$ 50) produced acetic acid, however, only one-third of women produced the other copulin components en bloc (Michael et al. 1975; Preti and Huggins 1975). Note, a follow-up study by Huggins and Preti (1981) did not find fluctuations in copulin concentrations corresponding with non-pill using women's reproductive cycle. Thus, the function of copulin, as well as whether individual differences exist in copulin production, is unknown. It has been speculated that copulins are a leaky cue to women's mate quality and reproductive status and men who are better at detecting concentration fluctuations may have a mating advantage (Williams and Jacobson 2016).

We know of only two published behavioral studies directly testing the effects of synthetic copulin on men's behavior (i.e., Jütte and Grammer 1997; Williams and Jacobson 2016). Jütte and Grammer (1997) found that men exposed to synthetic copulin exhibited an increase in testosterone levels and were inhibited in their ability to discriminate female attractiveness, meaning their assessments of the attractiveness of female faces were higher on a scaled rating system and less varied, which may be due to a ceiling effect. In a follow-up study, Williams and Jacobson (2016) failed to replicate the attractiveness finding, though their results trended towards significance. The researchers did, however, find that men rated themselves more sexually desirable when exposed to copulin (Williams and Jacobson 2016). Steinbach et al. (2012) exposed men to liquid synthetic copulin while playing a tragedy of the commons game and found they were significantly more likely to cooperate. These mixed findings could be due to methodological limitation such as differences in exposure technique, small sample sizes and sampling variation.

Previous copulin studies have failed to acknowledge associative learning as a potential mechanism. The pleasurable sensation of sexual arousal could become associated with copulin odor such that future copulin exposure could prime past sexual experiences and affect behavior and physiology (Trotier 2011). This does not preclude the hypothesis that copulin detection has been selected for in men. Men may have a biological predisposition to learn via sexual experience the association between copulin concentration and ovulatory status. For example, Knaapila et al. (2012) found that only sexually experienced women rated androstenone as pleasant and suggested the odor of androstenone acquired a hedonic value from the past sexual context in which it was 
encountered. Cerda-Molina et al. (2013) conjectured that because the chemicals found in vaginal secretions are also found in vinegar, fruits, etc., it is only via its association with sexual experience that vaginal secretion could influence men's sexual arousal.

The current study is the first to empirically test the effects of synthetic copulin on men's sexual behavior whilst exploring prior sexual experience as a possible mediator. In addition to examining the role of past sexual experience and varying the location of copulin exposure (e.g. olfactory epithelium versus epidermal keratinocytes in the genital region), we address some of the limitations of past research. Specifically, we employ a placebo-controlled, odor masking design using a large sample of men. Odor masking was used to blind the experimenter to the condition and to increase ecological validity as many scented products, like perfumes, are used in modern settings. Also, to better approximate real-world settings, participants were asked to rate female faces for attractiveness during the exposure phase of the study, such that they smell copulin whilst in a mating mindset. We seek not only to replicate previous findings, but also to extend upon this research by examining additional behavioral outcomes including sexual risk-taking, sexual motivation, preference for short-term versus long-term mating and self-perceived mate value.

\section{Material and Methods}

\section{Participants}

We recruited 243 male participants from a large, Ivy League university in an urban setting. Eligibility requirements included heterosexual orientation, no use of psychotropic medication or steroids, no cigarette smoking, and no nasal congestion or other known olfactory conditions that may impede the ability to smell. However, $n=12$ participants that completed the study self-identified as non-heterosexual and were excluded prior to performing any analyses. Of the recruited participants, $n=168$ received research credits and the remaining $n=75$ were paid $\$ 10$. Excluding the latter group from analysis did not change results. We analyzed a sample of 231 out of the recruited 243 participants. The sample has a mean age of $20.92(S D=3.90)$. Participants identified as White $(n=135)$, Black $(n=22)$, Asian $(n=66)$ and other $(n=10)$. Approximately three quarters $(71.3 \%)$ of participants identified as single, while the rest reported being in a relationship. The university's Office of Regulatory Affairs approved all procedures.

\section{Procedures}

The experiment was conducted in a non-deception lab; thus, participants were told the research objective was to examine the role of a "potential female pheromone" in sexual attraction and that they may or may not be exposed to a potential pheromone. Each session consisted of 1-5 participants and the same female graduate student oversaw each session. We initially employed a double-blind design by having a graduate student not affiliated with the study assign labels A and B to the containers containing the mixtures and asked that he keep the code locked away until after analysis. However, the mixtures smelled differently and the graduate student running the sessions correctly 
guessed which container held the copulin mixture and began to discriminate the two odors, thus double-blinding was unable to be maintained throughout the study. Using a random number generator, participants were assigned to one of four conditions: nasal exposure, genital exposure, both genital and nasal exposure, neither genital nor nasal exposure/control. In all conditions, a facemask was worn over the nose and gauze was placed over the genitals. After consenting to the study, participants were first given a facemask to wear over their nose; this not only tested the nasal pathway but also kept participants from being nasally exposed to the genital gauze odor. They were then given gauze to place inside their pants but over their underwear in the genital region. They were specifically advised to not allow the gauze to make direct contact with their skin.

The facemask and gauze were treated with $5 \mathrm{ml}$ of mixture via pipetting. Facemask and genital gauze were treated according to participant condition (e.g. nasal exposure, genital exposure, both genital and nasal exposure and neither genital nor nasal exposure/control), see Table 1). Participants were blind to their condition.

After participants put on their facemask and placed the gauze in their pants, they completed a survey that included basic demographic questions. Participants also provided attractiveness assessments for thirty photographed women's faces. Together, these tasks took approximately $15 \mathrm{~min}$. Following this, participants removed their facemasks and gauze pad. Participants then completed surveys to measure selfperceived mate value, preference for long versus short-term mating, sexual risk-taking, sexual history and completed a task to measure sexual motivation by choosing whether to view sexually explicit images. Finally, participants watched a 5-min video clip about plants to eliminate any potential embarrassment in the event that they were aroused during the study. Participants were debriefed and thanked.

\section{Measures}

Synthetic Copulin $100 \mathrm{~mL}$ of synthetic copulin was produced according to the concentration at ovulation recorded by Michael et al. (1975; see Appendix Table 5). This solution was diluted to $0.08 \mathrm{~mL}$ of copulins per $1 \mathrm{~mL}$ of distilled water. This is the concentration of copulin used in previous studies (Jütte and Grammer 1997; Williams and Jacobson 2016; Steinbach et al. 2012). The method of production was obtained via personal communication with Oberzaucher (October 7, 2013) and Steinbach (November 15,2013$)$. To mask the scent of copulin, $12.5 \mathrm{~g}$ of vanillin were added to the mixture (Sigma-Aldrich, St. Louis). Vanillin was chosen because it is often used in women's perfumes. The control solution consisted of $12.5 \mathrm{~g}$ of vanillin mixed with $1.25 \mathrm{~L}$ of distilled water. Both mixtures were refrigerated and stored in scientific-glass containers labeled with A or B. $5 \mathrm{~mL}$ of experimental or control solution was applied

Table 1 Conditions by area of exposure and mixture to which exposed

\begin{tabular}{llllr}
\hline Area of exposure & Conditions & & & \\
\cline { 2 - 5 } & Nasal & Genital & Both & Neither \\
\hline Nasal & Copulin & Control & Copulin & Control \\
Genital & Control & Copulin & Copulin & Control \\
\hline
\end{tabular}


using a glass pipette to a gauze pad for genital exposure and a gauze pad safety pinned inside a facemask for nasal exposure.

Attractiveness Assessment Participants were presented with 30 photographs of Caucasian women baring neutral expressions taken from the Karolinska Directed Emotional Faces (KDEF) set and asked to rate their attractiveness on a 5-point scale, with 1 indicating very unattractive and 5 indicating very attractive.

Mate Value Participants used a 7-point scale to rate self-perceived mate quality using the Mate Value Scale (MVS). This is a 4-item measure taken from Edlund and Sagarin (2014, see Appendix Table 6). A higher score indicates higher self-perceived mate value.

Preference for Short-Term Versus Long-Term Mating Participants preferences for short-term versus long-term mating strategies were assessed using the revised Sociosexual Orientation Inventory (SOI-R 5-pt. response scale) (Penke and Asendorpf 2008, see Appendix Table 7). Higher scores indicate a preference for short-term mating.

Sexual Risk-Taking Participants were asked eight questions on their willingness to engage in risky sexual practices taken from Ariely and Loewenstein (2006). Responses were made on a sliding scale that stretched between "no" (0) to "possibly" (50) to "yes" (100). An example question is as follows: Would you trust a woman you've just met who says she is using birth control?

Sexual Motivation Participants completed 10 sessions of a "sorting task" that required them to categorize a series of numbers as either odd or even. Before each session they were given a choice to view either a sexually explicit photograph or a nature scene photograph. When making the choice, participants were told that selecting the sexually explicit photograph would result in having to sort 8 numbers as odd or even in that session, whereas choosing the nature scene would only result in sorting 5 numbers. The number of times a participant chose to view sexually explicit photographs was summed and used as a measure of sexual motivation. Nature scene photos were scored as one and sexual photos were scored as two giving a range of scores from 10 to 20. Stimuli were selected from the International Affective Picture System (IAPS).

Sexual Experience We collected binary measures of virginity. Participants were asked whether they ever had either vaginal sex and oral sex before.

Probe For the final measure, participants were asked whether or not they thought they were exposed to a female pheromone during the experiment.

\section{Result}

All statistical tests were two-tailed. Table 2 reports descriptive statistics for the entire sample and disaggregated by condition. Preliminary analyses were conducted to determine equivalence across the four conditions on demographic characteristics (race, 
age, relationship status and virginity). A Chi-Square Test of Independence was used to assess whether the proportion of different race categories varied across conditions. The finding was not significant $\chi^{2}=(9,230)=5.40, p=.80$. No differences in the number of virgins $\chi^{2}=(3,229)=3.07, p=.38$ or relationship status $\chi^{2}=(3,230)=3.81, p=.28$ between the conditions were found. A one-way ANOVA revealed that age $F$ (3, $225)=.61, p=.61$ also did not vary between conditions.

There was no indication that participants correctly identified whether or not they were exposed to copulin $\chi^{2}=(3,227)=2.42, p=.49$. Participant responses to the probe question were also equally distributed across the four conditions, $\chi^{2}=(3,229)=2.22$, $p=.53$. Furthermore, virgins and non-virgins did not vary in answer accuracy to the probe question $\chi^{2}=(1,229)=.97, p=.32$. In addition, exploratory analysis revealed that there was not a placebo effect of participants thinking they were exposed to copulin on any of the dependent variables. That is, $t$-tests revealed mean ratings of the attractiveness of the face stimuli $t(224)=-0.16, p=.87$, variance in participant ratings of the face stimuli's attractiveness $t(227)=-1.05, p=.29$, self-reported mate value $t$ $(227)=.65, p=.51$, preference for short-term versus long-term mating $t(227)=.61$, $p=.55$, sexual risk-taking $t(227)=-0.46, p=.65$ and sexual motivation $t(227)=$ $-1.56, p=.12$ did not vary between those who thought that they were exposed to copulin and those who did not.

A Shapiro-Wilk test was used to test for normality on the main dependent variables mean attractiveness ratings, variance in within participant ratings of the face stimuli's attractiveness, self-reported mate value, preference for short-term versus long-term mating, sexual risk-taking, and sexual motivation; variance in within participant ratings of the face stimuli's attractiveness, self-reported mate value, preference for short-term versus long-term mating and sexual motivation were non-normal $(p>.05)$. Levene's test for equality of variance was not violated for attractiveness ratings $F(3,224)=.77$, $\mathrm{p}=.51$, variance in attractiveness ratings $F(3,228)=1.68, p=.17$, self-reported mate value $F(3,227)=1.16, p=.33$, preference for short-term vs. long-term mating $F(3$, $227)=1.24, p=.30$, sexual risk-taking $F(3,227)=.32, p=.81$, or sexual motivation $F(3,227)=.30 p=.83$.

Table 2 Descriptive statistics of age, ethnicity, relationship status and virginity in the full sample and by condition

\begin{tabular}{llllll}
\hline & Neither & Genital & Nasal & Both & Total \\
\hline$N$ & 57 & 60 & 57 & 56 & 230 \\
Age & $21.32(4.60)$ & $21.20(5.26)$ & $20.54(2.01)$ & $20.59(2.69)$ & $20.92(3.90)$ \\
White & 56.1 & 56.7 & 63.2 & 58.9 & 58.7 \\
Black & 10.5 & 6.7 & 14.0 & 7.1 & 9.6 \\
Asian & 29.8 & 30.0 & 21.1 & 28.6 & 27.4 \\
Other & 3.5 & 6.7 & 1.8 & 5.4 & 4.3 \\
Relationship status (single) & 64.9 & 78.3 & 75.4 & 66.1 & 71.3 \\
Sexual experience (virgin) & 24.6 & 26.7 & 15.8 & 28.6 & 24.0 \\
\hline
\end{tabular}

Standard deviations are in parentheses. Proportions are reported for ethnicity, relationship status and virginity for the full sample and by condition 
Table 3 provides means and standard deviations of each dependent variable by condition. Five separate one-way ANOVAs were computed to test the effects of copulin exposure on our six main dependent variables. While we report results from ANOVAs, the non-parametric Kruskal-Wallis test did not yield meaningfully different results. Mean attractiveness ratings significantly varied between groups $F(3, N=222)=3.25$, $p=.02$, but in the opposite direction predicted. Post hoc comparisons using Tukey HSD indicated that the mean score for the condition with copulin exposure in both locations (nasal and genital) was borderline significantly lower on average than the condition of exposure to control mixture in both locations $p=.05$. Variance in within-in participant attractiveness ratings across faces $F(3,226)=2.23, p=.09$, self-perceived mate value $F(3,225)=.40, p=.75$, preference for short-term versus long-term mating $F(3$, $225)=.13, p=.94$, sexual risk-taking $F(3,225)=.55, p=.65$ and sexual motivation $F(3,225)=1.03, p=.38$ did not vary by condition.

Separate $2 \times 4$ ANOVAs were also conducted to examine the effect of virginity (Factor A) and treatment type (Factor 5) on our dependent variables. A Phi-Coefficient test was used to assess the correlation between oral and vaginal sex virginity. Oral sex virginity was highly correlated with vaginal virginity, $\phi=.71, p<.001$ and thus no separate analyses were run to examine the effect of oral sex exposure. Only one of the models was significant (see Table 4). There was no interaction with virginity $F$ (3, $218)=.07, p=.98$ or main effect of virginity $F(1,218)=.38, p=.54$ on mean levels of attractiveness. When examining variance in attractiveness ratings of the face stimuli, there was a main effect of virginity $F(1,221)=5.54, p=.02$, no main effect of treatment type $F(3,221)=.91, p=.44$, and an interaction $F(3,221)=2.95, p=.03$. A separate ANOVA for virgins and non-virgin was run with post-hoc comparisons using Tukey HSD revealing that when non-virgins were exposed to copulin nasally and genitally, they became significantly less discerning on average (exhibited reduced variance in within participant ratings of the face stimuli) than participants exposed to control in both locations $p=.05$. We also found a main effect of virginity $F(1,221)=$ $17.31, p<.001$ on self-reported mate value - with virgins reporting lower mate value, but no main effect of treatment type $F(3,221)=.96, p=.41$ or their interaction $F(3$, $221)=1.21, p=.31$ was found. Similarly, when examining short-term vs. long-term mating, we found a main effect of virginity $F(1,221)=50.67, p<.001$, where virgins reported greater preferences for long-term mating, but no main effect of treatment type $F(3,221)=.07, p=.98$ or their interaction $F(3,221)=.42, p=.74$ was found. When

Table 3 Means and standard deviations for each dependent variable by condition

\begin{tabular}{lllll}
\hline Measure & Neither & Genital & Nasal & Both \\
\hline Attractiveness mean & $2.29(0.61)$ & $2.17(0.49)$ & $2.19(0.55)$ & $1.98(0.49)$ \\
Attractiveness variance & $0.82(0.40)$ & $0.76(0.32)$ & $0.75(0.31)$ & $0.66(0.30)$ \\
Mate value score & $5.12(0.93)$ & $5.31(0.88)$ & $5.16(1.00)$ & $5.19(1.16)$ \\
Preference for short vs. long-term mating & $9.18(2.67)$ & $9.36(2.52)$ & $9.40(2.35)$ & $9.16(2.79)$ \\
Sexual risk-taking & $67.00(13.53)$ & $65.15(13.51)$ & $68.19(15.04)$ & $67.78(13.21)$ \\
Sexual motivation & $13.14(2.86)$ & $14.00(3.11)$ & $13.91(3.04)$ & $13.43(3.13)$ \\
\hline
\end{tabular}

Standard deviations are in parentheses 
Table 4 Means and standard deviations (in parentheses) for each dependent variable by condition and disaggregated by sexual experience

\begin{tabular}{llllll}
\hline Measure & Sexual experience & Neither & Genital & Nasal & Both \\
\hline Attractiveness mean & Virgin & $2.30(0.84)$ & $2.13(0.49)$ & $2.13(0.63)$ & $1.92(0.57)$ \\
& Non-Virgin & $2.29(0.52)$ & $2.18(0.49)$ & $2.21(0.54)$ & $2.01(0.46)$ \\
Attractiveness variance & Virgin & $0.54(0.32)$ & $0.69(0.28)$ & $0.78(0.22)$ & $0.63(0.35)$ \\
& Non-Virgin & $0.92(0.38)$ & $0.79(0.34)$ & $0.74(0.33)$ & $0.68(0.28)$ \\
Mate value score & Virgin & $4.48(1.27)$ & $5.06(0.95)$ & $4.86(1.28)$ & $4.50(1.38)$ \\
& Non-Virgin & $5.33(0.69)$ & $5.41(0.85)$ & $5.22(0.95)$ & $5.47(0.94)$ \\
Preference for short vs & Virgin & $7.48(1.82)$ & $7.25(1.82)$ & $7.56(1.57)$ & $6.90(1.88)$ \\
long-term mating & Non-Virgin & $9.74(2.69)$ & $10.14(2.30)$ & $9.75(2.33)$ & $10.07(2.59)$ \\
Sexual risk-taking & Virgin & $66.32(18.03)$ & $57.28(14.96)$ & $60.26(21.24)$ & $62.72(10.11)$ \\
& Non-Virgin & $67.22(11.97)$ & $68.08(11.84)$ & $69.67(13.34)$ & $69.80(13.85)$ \\
Sexual motivation & Virgin & $12.79(3.09)$ & $14.00(3.61)$ & $12.89(3.26)$ & $13.81(4.13)$ \\
& Non-Virgin & $13.26(2.81)$ & $14.00(2.95)$ & $14.10(2.99)$ & $13.28(2.67)$ \\
\hline
\end{tabular}

looking at variance in sexual risk-taking, a main effect of virginity $F(1,221)=10.84$, $p<.001$ was found, where virgins reported less willingness to take risks, but no main effect of treatment type $F(3,221)=.82, p=.48$ or their interaction $F(3,221) 1.10$, $p=.35$ was found. Finally, when examining sexual motivation, no main effect of virginity $F(1,221)=.35, p=.55$ or treatment type $F(3,221)=.76, p=.52$ or their interaction $F(3,221)=.55, p=.65$ was found.

\section{Discussion}

Previous studies have reported an effect of copulin exposure on men's testosterone levels, perception of women's attractiveness (Jütte and Grammer 1997), cooperation (Steinbach et al. 2012) and self-reported mate value (Williams and Jacobson 2016). In the largest study on copulin to date, utilizing two different routes of exposure, we found no evidence that copulin affect men's sexual motivation, self-reported willingness to take sexual risks, preference for short-term mating over long-term mating, perceptions of female attractiveness or self-reported mate value. We also found no mediation effects of prior sexual experience on any of our dependent measures. While the current study deviated from the methodology of Jütte and Grammer (1997) in that they used gaseous synthetic copulin, it was consistent with Steinbach et al. (2012) and Williams and Jacobson (2016), who both used liquid copulin produced in the same manner as the current study.

Based on the current results, we argue that copulin should stop being termed a putative human pheromone or even a chemical signal. To achieve this status, the following criteria would need to be demonstrated (see Wyatt 2014): 1) synthesized copulin should produce the same behavioral and physiological reactions in conspecifics as naturally produced copulin and at equivalent concentrations as naturally produced copulin 2) that each constituent acid of the copulin mixture should be necessary and 
sufficient to cause said reaction(s) 3) that only the proposed mixture of chemicals should elicit these reactions 4) that a credible pathway evolved to facilitate copulin communication and 5) that the quantities of copulin may vary between individuals of different, for example, mate quality or status, but individuals themselves cannot be recognized by the copulin they produce. Our study demonstrates the failure of the very first criteria.

There are a number of potential limitations with the current study. First, we implemented a masking technique to increase ecological validity since perfume and other fragranced products (e.g. soap) are used regularly. Copulin without any masking, as used in previous designs, was not assessed; therefore, we cannot conclude whether unmasked copulin would have yielded significant findings. However, olfactory processing, unlike other sensory systems, is not additive, meaning there is no mixing of molecules (Carlson 2013). Consequently, masking techniques are not expected to impact the olfactory systems unconscious processing of odors - only the conscious perception of the smell. Whereas other sensory systems project directly to the thalamus, the brain region that integrates sensory information and is suggested to be where conscious perception comes online, the olfactory system first projects to the olfactory cortex, then the amygdala, insular cortex, hypothalamus (or hippocampus) and then finally to the thalamus. Thus, odorant molecules can affect physiology and behavior before conscious awareness of an odor (Carlson 2013; Wyatt 2014; Parma et al. 2017).

A second limitation may have to do with the use of vanillin as the masking agent and control. Vanillin is used as a base note in many perfumes; therefore, men may associate vanillin with a pleasant feminine scent. Any scent men associate with women could increase sexual arousal and result in higher scores for all participants. However, this was not likely to be a significant limitation as participant scores were low on average. Future work could examine the role of copulin without masking or use different masking odorants. A third limitation is the possibility of "leaky" odors. Because all participants were run in the same laboratory space it is possible that everyone was exposed to the copulin odor upon entering the lab. We minimized this potential problem by having participants don surgical face masks over their noses and mouths prior to data collection. However, future research could benefit from running participants in the different conditions on different days or in different rooms in order to eliminate or reduce the possibility of odor "leakage." A final limitation of our design stems from informing participants of their possible exposure to a "putative female pheromone" which could have inadvertently primed sexual behavior. We think this unlikely however, because we found no effect of whether participants thought they were exposed to copulin on any of our dependent measures.

While we failed to find an effect of copulin, this does not mean human olfaction is poor, or that chemosensory communication does not exist in humans. Recent work suggests body odors constitute a special subclass of ecologically relevant odors that influence mate preference (for review, Grammer et al. 2005) and have implications for health (Whittle et al. 2007; Prugnolle et al. 2009; Moshkin et al. 2012; Olsson et al. 2014). Humans are able to discriminate body odors from sick and healthy individuals (Olsson et al. 2014). PET and fMRI studies demonstrate separate olfactory processing for common odors (e.g. lavender) and body odors. This may suggest, similar to faces, body odors contain evolutionarily significant information and thus utilize a special processing region akin to the fusiform face area (Parma et al. 2017). Heterosexual 
women and homosexual men exhibit activation of the anterior hypothalamus in addition to primary olfactory cortex when exposed to androstenol, a testosterone derivative found in post-pubertal male axillary secretions. In contrast, exposure to nonbody odors resulted only in activation of primary olfactory cortex (Savic and Berglund 2010). Homosexual women and heterosexual men process androstenol in primary olfactory cortex and estra-1, 3, 5 (10), 16-tetraen-3-ol, found in female urinary secretions, in the anterior hypothalamus (Berglund et al. 2006). Brain imaging evidence, as a whole, suggests the potential for body odors to strongly influence human social behaviors.

There are no definitive human pheromones to date. The quest continues, but we argue that in the future, researchers should focus on individual's chemical profiles instead of trying to identify a specific human pheromone. To identify a specific molecule or mixture of molecules as a pheromone, researchers would need to satisfy points one through five mentioned above and show the proposed pheromone is a species-wide signal and results in universal stereotyped physiological and/or behavioral reactions in a conspecific (Wyatt 2014). For now, it may be more worthwhile to devote efforts on determining what internal and external components construct an individual's chemical profile, how the secretory environment (e.g. hair) impacts odor production and how these inputs affect social assessments, like mate choice, and behavioral outputs. Once we have a strong theoretical framework for what evolutionarily significant information may be present in body odors, only then can we perform meaningful empirical studies. Identifying a specific molecule(s) that occur within the backdrop of all human's chemical profiles and results in stereotyped reactions in conspecifics will require rigorous bioassay testing, behavioral studies and, we predict, many decades of research.

\section{Conclusion}

Odors permeate all aspects of human life and yet, skepticism surrounding the relevance of odors in human social behavior remains. Some of the reluctance to acknowledge the importance of smell in humans may be partly due to older conceptual and largely erroneous views of how chemical signaling works. While we find no evidence that copulin is involved in men's sexual behavior, we advocate for more research examining the effects of human body odor on social behavior.

Acknowledgements We thank Dr. Loretta Flanagan-Cato for use of her laboratory and guidance in producing the copulin mixture. We also thank Dr. Amy Jacobson and all members of the Pennsylvania Lab for Experimental Evolutionary Psychology for their incisive feedback throughout the entirety of this project.

Author Contribution MW and CA designed the study and wrote the paper. MW collected the data and analyzed the results.

Funding This research did not receive any specific grant from funding agencies in the public, commercial, or not-for-profit sectors, however we do thank the University of Pennsylvania Department of Psychology for funding.

\section{Compliance with Ethical Standards}

Conflict of Interest The authors express no conflict of interest. 


\section{Appendix 1}

Table 5 Concentrations of fatty acids found in vaginal secretions from three separate phases of the menstrual cycle (Michael et al. 1975)

\begin{tabular}{lccc}
\hline & \multicolumn{3}{c}{ Volume-percent of acids in vaginal secretions } \\
\cline { 2 - 4 } & Menstruation (day 2) & Ovulation (day 14) & Premenstruation (day 29) \\
\hline Acetic acid & 95.2 & 78.38 & 97.54 \\
Propanoic acid & 2.32 & 13.21 & 1.45 \\
Butanoic acid & 1.20 & 4.94 & 0.50 \\
Methylpropanoic acid & 0.32 & 0.76 & 0.30 \\
Methylbutanoic acid & 0.97 & 2.14 & 0.21 \\
\hline
\end{tabular}

Synthetic copulin were produced according to menstrual day 14 data. Meaning, the percentages of each acid per $100 \mathrm{~mL}$ are as followed: $78.38 \%$ acetic acid, $13.21 \%$ propanoic acid, $4.94 \%$ butanoic acid, $0.76 \%$ methylpropanoic acid, and 2.14\% methylbutanoic acid (Sigma-Aldrich, St. Louis)

\section{Appendix 2}

Table 6 Edlund and Sagarin (2014) mate value scale

\begin{tabular}{|c|c|c|c|c|c|c|c|}
\hline \multicolumn{8}{|l|}{ Mate value scale } \\
\hline $\begin{array}{l}\text { Overall, how would } \\
\text { you rate your } \\
\text { level of desirability } \\
\text { as a partner? }\end{array}$ & $\begin{array}{l}1 \\
\text { Extremely } \\
\quad \text { undesirable }\end{array}$ & 2 & 3 & 4 & 5 & 6 & $\begin{array}{l}7 \\
\text { Extremely } \\
\text { desirable }\end{array}$ \\
\hline $\begin{array}{l}\text { Overall, how would } \\
\text { members of the } \\
\text { opposite sex rate } \\
\text { your level of } \\
\text { desirability as } \\
\text { a partner? }\end{array}$ & $\begin{array}{l}1 \\
\text { Extremely } \\
\quad \text { undesirable }\end{array}$ & 2 & 3 & 4 & 5 & 6 & $\begin{array}{l}7 \\
\text { Extremely } \\
\text { desirable }\end{array}$ \\
\hline $\begin{array}{l}\text { Overall how do } \\
\text { you believe you } \\
\text { compare to other } \\
\text { people in desirability } \\
\text { as a partner? }\end{array}$ & $\begin{array}{l}1 \\
\text { Very much } \\
\quad \begin{array}{l}\text { lower than } \\
\text { average }\end{array}\end{array}$ & 2 & 3 & 4 & 5 & 6 & $\begin{array}{l}7 \\
\text { Very much higher } \\
\text { than average }\end{array}$ \\
\hline $\begin{array}{c}\text { Overall, how good of } \\
\text { a catch are you? }\end{array}$ & $\begin{array}{l}1 \\
\text { Very bad catch }\end{array}$ & 2 & 3 & 4 & 5 & 6 & $\begin{array}{l}7 \\
\text { Very good catch }\end{array}$ \\
\hline
\end{tabular}




\section{Appendix 3}

Table 7 Question used from Penke and Asendorpf (2008) SOI-R (Our measure of short-term vs. long-term mating preference)

Revised sociosexual orientation inventory

With how many different partners have you had sec within the past 12 months?

With how many different partners have you had sexual intercourse on one and only one occasion?

With how many different partners have you had sexual intercourse without having an interest in a long-term committed relationship with this person?

Sex without love is okay.

I do not want to have sex with a person until I am sure that we will have a long-term, serious relationship.

I can imagine myself being comfortable and enjoying casual sex with different partners.

How often do you have fantasies bout having sex with someone you re not in committed relationship with?

How often do you experience sexual arousal when you are in contact with someone you are not in a committed romantic relationship with?

In everyday life, how often do you have spontaneous fantasies bout having sex with someone you have just met?

Open Access This article is distributed under the terms of the Creative Commons Attribution 4.0 International License (http://creativecommons.org/licenses/by/4.0/), which permits unrestricted use, distribution, and reproduction in any medium, provided you give appropriate credit to the original author(s) and the source, provide a link to the Creative Commons license, and indicate if changes were made.

\section{References}

Ariely, D., \& Loewenstein, G. (2006). The heat of the moment: the effect of sexual arousal on sexual decision making. Journal of Behavioral Decision Making, 19, 87-98.

Barton, R. (2006). Olfactory evolution and behavioral ecology in primates. American Journal of Primatology, $68,545-558$.

Barton, R. A., Purvis, A., \& Harvey, P. H. (1995). Evolutionary radiation of visual and olfactory brain systems in primates, bats and insectivores. Philosophical Transactions of the Royal Society of London B Biological Sciences, 348(1326), 381-392.

Berglund, H., Lindstrom, P., \& Savic, I. (2006). Brain response to putative pheromones in lesbian women. Proceedings of the National Academy of Sciences, 103(21), 8269-8274.

Black, S., \& Biron, C. (1982). Androstenol as a human pheromone: no effect on perceived physical attractiveness. Behavioral and Neural Biology, 34(3), 326-330.

Brooksbank, B., \& Haslewood, W. (1961). The estimation of androst-16-en 3a-ol in human urine. Partial synthesis of androstenol and of its b-glucosiduronic acid. Biochemical Journal, 80, 488-496.

Bushdid, C., Magnasco, M. O., Vosshall, L. B., \& Keller, A. (2014). Humans can deterct more than 1 trillion olfactory stiumuli. Science, 343, 1370-1372.

Busse, D., Kudella, P., Grüning, N., Gisselmann, G., Ständer, S., Luger, T., Jacobsen, F., Steinsträßer, L., Paus, R., Gkogkolou, P., Böhm, M., Hatt, H., \& Benecke, H. (2014). A synthetic sandalwood odorant induces wound-healing processes in human keratinocytes via the olfactory receptor OR2AT4. Journal of Investigative Dermatology, 134, 2823-2832.

Carlson, N. (2013). Physiology of behavior (11th ed.). Boston: Pearson. 
Cerda-Molina, A., Hernandez-Lopez, L., Rojas-Maya, S., Murcia-Mejia, C., \& Mondragon-Ceballos, R. (2006). Male-induced sociosexual behavior by vaginal secretions in Macaca arctoides. International Journal of Primatology, 27(3), 791-807.

Cerda-Molina, A., Hernandez-Lopez, L., De la, O. C. E., Chavira-Ramirez, R., \& Mondragon-Ceballos, R. (2013). Changes in men's salivary testosterone and cortisol levels, and in sexual desire after smelling female axillary and vulvar scents. Frontiers in Endocrinology, 4, 1-9.

Cleveland, W., \& Savard, K. (1964). Studies of excretion of androst-16-en 3a-ol. Journal of Clinical Endocrinology and Metabolism, 24, 983-987.

Cutler, W., Friedmann, E., \& McCoy, N. (1998). Pheromonal influences on the sociosexual behavior of men. Archives of Sexual Behavior, 27, 1-13.

Dorries, K., Regan, E., \& Halpern, B. (1997). Sensitivity and behavioral responses to the pheromone androstenone are not mediated by the vomeronasal organ in pigs. Brain, Behavior and Evolution, 49, 53-62.

Doty, R. L., Ford, M., Preti, G., \& Huggins, G. R. (1975). Changes in the intensity and pleasantness of human vaginal odors during the menstrual cycle. Science, 190(4221), 1316-1318.

Edlund, J. E., \& Sagarin, B. J. (2014). The mate value scale. Personality and Individual Differences, 64, 7277.

Engen, T. (1983). The human uses of olfaction. American Journal Otolaryngology, 4, 250-251.

Epple, G. (1986). Communication by chemical signals. Comparative Primate Biology, 2(Part A), 531-580.

Epple, G., Belcher, A. M., \& Smith, A. B. (1986). Chemical signals in Callitrichid monkeys- a comparative review. In D. Duvall, D. Müller-Schwarze, \& R. M. Silverstein (Eds.), Chemical signals in vertebrates 4 (pp. 653-672). New York: Springer US.

Goldfoot, D. A., Kravetz, M. A., Goy, R. W., \& Freeman, S. K. (1976). Lack of effect of vaginal lavages and aliphatic acids on ejaculatory responses in rhesus monkeys: behavioral and chemical analyses. Hormones and Behavior, 7(1), 1-27.

Grammer, K., Fink, B., Moller, A., \& Thornhill, R. (2003). Darwinian aesthetics: sexual selection and the biology of beauty. Biological Reviews, 78, 385-407.

Grammer, K., Fink, B., \& Neave, N. (2005). Human pheromones and sexual attraction. European Journal of Obstetrics, Gynecology, and Reproductive Biology, 118(2), 135-142.

Griffin, C., Kafadar, K., \& Pavlath, G. (2009). MOR23 promotes muscle regeneration and regulates cell adhesion and migration. Developmental Cell, 17(5), 649-661.

Grus, W. E., Shi, P., Zhang, Y. P., \& Zhang, J. (2005). Dramatic variation of the vomeronasal pheromone receptor gene repertoire among five orders of placental and marsupial mammals. Proceedings of the National Academy of Sciences of the United States of America, 102(16), 5767-5772.

Gu, X., Karp, P., Brody, S., Pierce, R., Welsh, M., Holtzman, M., \& Ben-Shahar, Y. (2014). Chemosensory functions for pulmonary neuroendocrine cells. American Journal of Respiratory Cell and Molecular Biology, 50(3), 637-664.

Haselton, M. G., \& Gildersleeve, K. (2011). Can men detect ovulation? Current Directions in Psychological Science, 20(2), 87-92.

Havlicek, J., \& Roberts, S. C. (2009). MHC-correlated mate choice in humans: a review. Psychoneuroendocrinology, 34, 497-512.

Herz, R., Beland, S., \& Hellerstein, M. (2004). Changing odor hedonic perception through emotional associations in humans. International Journal of Comparative Psychology, 17, 315-338.

Hudson, R., \& Distel, H. (1986). Pheromonal release of suckling in rabbits does not depend on the vomeronasal organ. Physiology and Behavior, 37(1), 123-128.

Huggins, G., \& Preti, G. (1981). Vaginal odors and secretions. Clinical Obstetrics and Gynecology, 24, 355377.

Jacob, S., McClintock, M., Zelano, B., \& Ober, C. (2002). Paternally inherited HLA alleles are associated with women's choice of male odor. Nature Genetics, 30, 175-179.

Jütte, A., \& Grammer, K. (1997). Der Kried der Düfte: Bedeutung der pheromone für die menschliche reproduktion. Gynäkologisch Geburtshifliche Rundschau, 37, 150-153.

Kaplan, J., Cubicciotti, D., \& Redican, W. (1977). Olfactory discrimination of squirrel monkey mothers by their infants. Developmental Psychobiology, 10, 447-453.

Knaapila, A., Tuorila, H., Vuoksimaa, E., Keskitalo-Vuokko, K., Rose, R. J., Kaprio, J., \& Silventoinen. (2012). Pleasantness of the odor of androstenone as a function of intercourse experience in women and men. Archives of Sexual Behavior, 41, 1403-1408.

Laska, M., \& Freyer, D. (1997). Olfactory discrimination ability for aliphatic esters in squirrel monkeys and humans. Chemical Senses, 22, 457-465. 
Laska, M., \& Teubner, P. (1998). Odor structure-activity relationships of carboxylic acids correspond between squirrel monkeys and humans. American Journal of Physiology - Regulatory, Integrative and Comparative Physiology, 274, R1639-R1645.

Laska, M., \& Teubner, P. (1999a). Olfactory discrimination ability for homologous series of aliphatic alcohols and aldehydes. Chemical Senses, 24, 263-270.

Laska, M., \& Teubner, P. (1999b). Olfactory discrimination ability of human subjects for ten pairs of enantiomers. Chemical Senses, 24, 161-170.

Laska, M., Wieser, A., \& Salazar, L. T. H. (2005). Olfactory responsiveness to two odorous steroids in three species of nonhuman primates. Chemical Senses, 30, 505-511.

Luscher, M., \& Karlson, P. (1959). "Pheromones": a new term for a class of biologically active substances. Nature, 183, 55-56.

Maddocks-Jennings, W., \& Wilkinson, J. M. (2004). Aromatherapy practice in nursing: literature review. Journal of Advanced Nursing, 48(1), 93-103.

Matsumoto-Oda, A., Oda, R., Hayashi, Y., Murakami, H., Maeda, N., Kumazaki, K., Shimizu, K., \& Matsuzawa, T. (2003). Vaginal fatty acids produced by chimpanzees during menstrual cycle. Folia Primatologica, 74, 75-79.

McCoy, N. L., \& Pitino, L. (2002). Pheromonal influences on sociosexual behavior in young women. Physiology and Behavior, 75(3), 367-375.

Michael, R., \& Keverne, E. (1968). Pheromones in the communication of sexual status in primates. Nature, 218, 746-749.

Michael, R. P., \& Zumpe, D. (1982). Influence of olfactory signals on the reproductive behavior of social groups of rhesus monkeys (Macaca mulatta). Journal of Endocrinology, 95, 189-205.

Michael, R., Keverne, E., \& Bonsall, R. (1971). Pheromones: isolation of male sex attractants from a female primate. Science, 172, 964-966.

Michael, R. P., Bonsall, R. W., \& Kutner, M. (1975). Volatile fatty acids, "copulins”, in Human vaginal secretions. Psychoendocrinology, 1, 153-163.

Miller, S. L., \& Maner, J. K. (2010). Scent of a woman: men's testosterone responses to olfactory ovulation cues. Psychological Science, 21, 276-283.

Miller, S. L., \& Maner, J. K. (2011). Ovulation as a male mating prime: subtle signs of women's fertility influence men's mating cognition and behavior. Journal of Personality and Social Psychology, 100(2), 295-308.

Millhollen, A. (1986). Territorial scent marking by two sympatric lemur species. In D. Duvall, D. MüllerSchwarze, \& R. M. Silverstein (Eds.), Chemical signals in vertebrates 4 (pp. 647-652). New York: Springer US.

Moshkin, M., Litvinova, N., Litvinova, E. A., Bedareva, A., Lutsyuk, A., \& Gerlinskaya, L. (2012). Scent recognition of infected status in humans. The Journal of Sexual Medicine, 9(12), 3211-3218.

Olsson, M. J., Lundström, J. N., Kimball, B. A., Gordon, A. R., Karshikoff, B., Hosseini, N., Sorjonen, K., Hoglund, O., Solares, C., Soop, A., Axelsson, J., \& Lekander, M. (2014). The scent of disease: human body odor contains an early chemosensory cue of sickness. Psychological Science, 25(3), 817-823.

Parma, V., Gordon, A., Cecchetto, C., Cavazzana, A., Lundstrom, J., \& Olsson, M. (2017). Processing of human body odors. In The handbook of olfaction, 1 ed.. Dordrecht, Heidelberg, London, New York: Springer International.

Penke, L., \& Asendorpf, J. B. (2008). Beyond global sociosexual orientations: a more differentiated look at sociosexuality and its effects on courtship and romantic relationships. Journal of Personality and Social Psychology, 95, 1113-1135.

Pluznick, J., Zou, D., Zhang, X., Yan, Q., Rodriguez-Gil, D., Eisner, C., Wells, E., Greer, C., Wang, T., Firestein, S., Schnermann, J., \& Caplan, M. (2009). Functional expression of the olfactory signaling system in the kidney. PNAS, 106(6), 2059-2064.

Porter, J., Craven, B., Khan, R. M., Chang, S. J., Kang, I., Judkewitz, B., Volpe, J., Settles, G., \& Sobel, N. (2007). Mechanisms of scent-tracking in humans. Nature Neuroscience, 10(1), 27-29.

Preti, G., \& Huggins, G. (1975). Cyclical changes in volatile acidic metabolites of human vaginal secretions and their relation to ovulation. Journal of Chemical Ecology, 1, 361-376.

Prugnolle, F., Lefevre, T., Renaud, F., Møller, A. P., Missé, D., \& Thomas, F. (2009). Infection and body odours: evolutionary and medical perspectives. Infection, Genetics and Evolution, 9, 1006-1009.

Rawson, N., Gomez, G., Cowart, B., Kriete, A., Pribitkin, E., \& Restrepo, D. (2012). Age-associated loss of selectivity in human olfactory sensory neurons. Neurobiology of Aging, 33, 1913-1919.

Roberts, S. C., Gosling, L. M., Carter, V., \& Petrie, M. (2008). MHC-correlated odour preferences in humans and the use of oral contraceptives. Proceeding of the Royal Society of London B, 275, 2715-2722. 
Rogel, M. J. (1978). A critical evaluation of the possibility of higher primate reproductive and sexual pheromones. Psychological Bulletin, 85(4), 810-830.

Santos, P. S. C., Schinemann, J. A., Gabardo, J., \& Bicalho, M. D. (2005). New evidence that the MHC influences odor perception in humans: a study with 58 southern Brazilian students. Hormones and Behavior, 47, 384-388.

Savic, I., \& Berglund, H. (2010). Androstenol-a steroid derived odor activates the hypothalamus in women. PLoS One, 5(2), e8651.

Savic, I., Berglund, H., Gulyas, B., \& Roland, P. (2001). Smelling odorous sex hormone-like compounds causes sex-differentiated hypothalamic activations in humans. Neuron, 31, 661-668.

Saxton, T. K., Lyndon, A., Little, A. C., \& Roberts, S. C. (2008). Evidence that androstadienone, a putative human chemosignal, modulates women's attributes of men's attractiveness. Hormones and Behavior, 54(5), 597-601.

Schleidt, M., \& Hold, B. (1982). Human odour and identity. In W. Breipohl (Ed.), Olfaction and endocrine regulation (pp. 181-194). Oxford, London: Information Retrieval Ltd..

Signoret, J. (1991). Sexual pheromones in the domestic sheep: importance and limits in the regulation of reproductive physiology. Journal of Steroid Biochemistry and Molecular Biology, 39, 639-645.

Singh, D., \& Bronstad, P. (2001). Female body odour is a potential cue to ovulation. Proceedings of the Royal Society of London B, 268, 797-801.

Smith, T. D., \& Bhatnagar, K. P. (2004). Microsmatic primates: reconsidering how and when size matters. Anatomical Record. Part B, New Anatomist, 279(1), 24-31.

Spehr, M., Gisselmann, G., Poplawski, A., Riffell, J., Wetzel, C., Zimmer, R., \& Hatt, H. (2003). Identification of a testicular odorant receptor mediating human sperm chemotaxis. Science, 299, 2054-2058.

Steinbach, X., Oberzaucher, E., \& Grammer, K. (2012). Human pheromones: Do "copulins" have an effect on mens testosterone levels and social behavior? (SFA). In XXI Biennial International Conference on Human Ethology Vienna/Austria.

Thornhill, R., Gangestad, S., Miller, R., Scheyd, G., Knight, J., \& Franklin, M. (2003). MHC, symmetry, and body scent attractiveness in men and women. Behavioral Ecology, 14, 668-678.

Trotier, D. (2011). Vomeronasal organ and human pheromones. European Annals of Otorhinolaryngology, Head and Neck Diseases, 128, 184-190.

Wedekind, C., \& Füri, S. (1997). Body odour preferences in men and women: do they aim for specific MHC combinations or simply heterozygosity? Proceedings of the Royal Society of London B, 264, 1471-1479.

Wedekind, C., Seebeck, T., Bettens, F., \& Paepke, A. J. (1995). MHC-dependent mate preference in humans. Proceedings of the Royal Society of London B, 260, 245-249.

Whittle, C. L., Fakharzadeh, S., Eades, J., \& Preti, G. (2007). Human breath odors and their use in diagnosis. Annals of New York Academy of Sciences, 1098, 252-266.

Williams, M. N., \& Jacobson, A. (2016). Effect of copulins on rating of female attractiveness, mate-guarding, and self-perceived sexual desirability. Evolutionary Psychology, 14(2), 1-8.

Witta, M., \& Wozniak, W. (2006). Structure and function of the vomeronasal organ. Advances in Oto-RhinoLaryngology, 63, 70-83.

Wyatt, T. D. (2014). Pheromones and animal behavior: Chemical signals and signatures (2nd ed.). Cambridge: Cambridge University Press. 